\title{
STUDY OF AIR FLOW IN A SOLAR COLLECTOR EQUIPPED WITH TWO INCLINED OBSTACLES
}

\author{
Fayssal Benosman ${ }^{1 *}$, and Mohammed Amine Amraoui ${ }^{1}$. \\ ${ }^{1}$ Faculty of Technology, Department of Mechanical Engineering, University Djillali LIABES Sidi-Bel-Abbès, BP 8922000 Sidi-Bel- \\ Abbès, Algeria
}

\begin{abstract}
In the present work we have studied the case of a conventional solar air collector and try to see how is it possible to improve it-s efficiency, by changing Reynolds number. Given the complexity of the problem we used the FLUENT calculation code. We made the mathematical model, then we gave a validation of our result by the results of Dimartini, we gave fields of speed, turbulence and a Nusselt profile and factor of friction as a function of the Reynolds Number. The results show that variation of Reynolds number has an influence on the performance of the solar collector, which is why we have used several values in order to observe the most suitable one.
\end{abstract}

\section{Introcution}

Several researches have been done in the field of solar collectors all with the aim of improving the performance of these

JALIL and AYAAL [1], studied the case with a simple solar collector, by varying the quantity of air admitted by the multiplication of the inputs from 1 to 3 , they obtained that the case with 3 inputs was the most suitable in order to obtain the highest value of the outlet temperature, for an inlet speed of $1.5 \mathrm{~m} / \mathrm{s}$ and a flow of $900 \mathrm{~W}$ the outlet temperature could expect $50^{\circ} \mathrm{C}$ with three inputs

Rodono and Volpes [2] have studied the behaviour of a flat solar collector during a period of 24 hours and have brought correlations making a relation between The radiant heat captured by a solar collector divided by three fraction, that transmitted by conduction, the other collected by the flow and the last reflected by the glazing. The purpose of these equations is to estimate the efficiency of the sensor.

Rodono and Volpes [3] also made a numerical simulation by finite difference method of a vertical solar collector like the one used for heating buildings, the heat transfer is done by free convection, the input data are the internal temperatures and external and solar power absorbed, however, this model remains simple and does not take into account the main climatic variables governing heat transfer processes, namely the temperature of the outside air.

Oudjedi et al [4] made an unsteady parametric study of a flat air solar collector intended for drying, they varied these parameters and found that, the variation of the air inlet temperature did not a great influence on that of its output, the latter decreases with the increase in the inlet speed, the efficiency increases with the increase in the inlet speed, and more the height of the channel increases more the efficiency decreases.

Aivars et al [5] made an experimental study by constructing a sensor of dimensions $0.1 \times 0.5 \times 1.0$ meters long in order to observe the influence of the nature of the materials used on the behavior of the sensor, they have found that The solar collector with a steelshin plate absorber in the middle is 2 times more effective as a collector with a steeltinplate absorber at the bottom.

Korobka et al [6] Have studied the influence of the value of the radiation on the output of the flat solar collector intended for drying the fruit, they found that for a radiation $\mathrm{E}=377 \mathrm{~W} / \mathrm{m} 2$ allows the output reached 70.7 $\%$ while for $\mathrm{E}=1000 \mathrm{~W} / \mathrm{m} 2$ on the contrary small $\eta=$ $54.6 \%$.

Mzad et al [7] wanted to determine the Optimization of the inclination and the orientation of the solar air collector with double glazing the interval of the angles of inclination is between $15^{\circ}, 35^{\circ}$ and also greater than $70^{\circ}$ They have found that for inclinations greater than $45^{\circ}$ the intensity of the power delivered by the sensor decreases the intensity of the power delivered by the sensor. While for tilt angles of $30^{\circ}$ to $45^{\circ}$ are even acceptable for lower azimuthal angles. This effectiveness also depends on the months of the year, during summer and better than during winter

Dimartini [8] is among the first to have made a dynamicstudy by introducing two baffles in a straight rectangular shape, one fixed on the absorber and the other on the insulator, the studyshowedthat the turbulence in this case was totally different., which gave the opportunity to a wide range of studies in thisfield by

* Corresponding author: benosman fayssal@yahoo.fr 
playing on the shape of the obstacles (geometry, location dimension and numbers).

In this study we are going to study the case of a solar collector provided with two obstacles in the form inclined at $45^{\circ}$ by varying the speed of air entry and therefore the Reynolds number and try to see the influence of this variation on sensor performance

\section{Analysis and modelling}

\subsection{Geometry}

Our study consists in taking a geometry that is similar to that of Dimartini [8], the difference is that for us the two baffles are placed on the lower part with identical dimensions and inclination angle as shown in figure 1, we vary the air inlet velocity to observe different Reynolds number and see its influence on the flow.

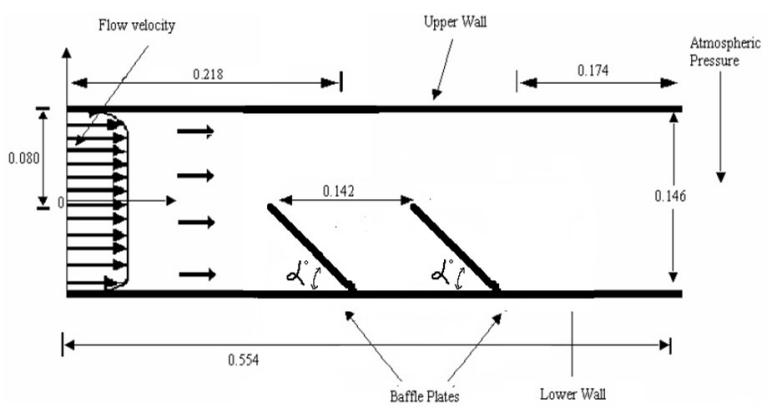

Fig. 1. Geometry of study

\subsection{Mathematical Model}

The studied problem is governed by the equations of conservation including the conservation of mass, momentum and energy.

\subsubsection{Conservation of mass}

$$
\frac{\partial(\rho u)}{\partial x}+\frac{(\rho v)}{\partial y}=0
$$

Where $: v$ Fluid velocity in $\mathrm{y}$-direction $(\mathrm{m} / \mathrm{s}) \cdot u$ Fluid velocity in $\mathrm{x}$-direction $(\mathrm{m} / \mathrm{s})$

\subsubsection{Conservation of momentum}

$$
\begin{gathered}
\rho u \frac{\partial u}{\partial x}+\rho v \frac{\partial u}{\partial y}=-\frac{\partial p}{\partial x}+\frac{\partial}{\partial x}\left[\left(\mu+\mu_{t}\right)\left(2 \frac{\partial u}{\partial x}\right)\right]+\frac{\partial}{\partial y}[(\mu+ \\
\left.\left.\mu_{t}\right)\left(\frac{\partial u}{\partial y}+\frac{\partial v}{\partial x}\right)\right]
\end{gathered}
$$

where: $\rho$ - Density $(\mathrm{kg} / \mathrm{m} 3), u$ Fluid velocity in $\mathrm{x}$ direction $(\mathrm{m} / \mathrm{s}) v$ Fluid velocity in $\mathrm{y}$-direction $(\mathrm{m} / \mathrm{s})-\mu$
The molecular viscosity (Pa.s)- $\mu$ t The turbulent (or eddy) viscosity (Pa.s)-P The static pressure (pa).

\subsubsection{Conservation of fluid energy}

$$
\rho u \frac{\partial T}{\partial x}+\rho v \frac{\partial T}{\partial y}=\frac{\partial}{\partial x}\left[\left(\frac{\mu}{P r}+\frac{\mu_{t}}{\sigma_{t}}\right) \frac{\partial T}{\partial x}\right]+\frac{\partial}{\partial y}\left[\left(\frac{\mu}{P r}+\frac{\mu_{t}}{\sigma_{t}}\right) \frac{\partial T}{\partial y}\right]
$$

where: $\rho$ - Density $(\mathrm{kg} / \mathrm{m} 3), u$ Fluid velocity in $\mathrm{x}$ direction $(\mathrm{m} / \mathrm{s}) v$ Fluid velocity in y-direction $(\mathrm{m} / \mathrm{s})-\mu$ The molecularviscosity (Pa.s)- $\mu \mathrm{t}$ The turbulent (or eddy) viscosity (Pa.s)-T Temperature (K)-Pr Molecular Prandtl number- $\sigma_{t}$ Turbulent Prandtl number for energy equation

\subsubsection{Turbulent kinetic energy $k$}

$\rho u \frac{\partial k}{\partial x}+\rho v \frac{\partial k}{\partial y}=\frac{\partial}{\partial x}\left[\left(\mu+\frac{\mu_{t}}{\sigma_{k}}\right) \frac{\partial k}{\partial x}\right]+\frac{\partial}{\partial y}\left[\left(\mu+\frac{\mu_{t}}{\sigma_{k}}\right) \frac{\partial k}{\partial y}\right]+P_{k}-$ $\rho \varepsilon$

where: $\rho$ - Density $(\mathrm{kg} / \mathrm{m} 3), u$ Fluid velocity in $\mathrm{x}$ direction $(\mathrm{m} / \mathrm{s}) v$ Fluid velocity in y-direction $(\mathrm{m} / \mathrm{s})-\mu$ The molecularviscosity (Pa.s)- $\mu \mathrm{t}$ The turbulent (or eddy) viscosity (Pa.s)- $k$ Turbulent kinetic energy, $\left(\mathrm{m}^{2} / \mathrm{s}^{2}\right)-\sigma_{k}$ Turbulent Prandtl number for K-equation $\varepsilon$ Specific dissipation rate, $\mathrm{m}^{2} / \mathrm{s} 3$.

\subsubsection{Dissipation energy $\varepsilon$}

$$
\begin{gathered}
\rho u \frac{\partial \varepsilon}{\partial x}+\rho v \frac{\partial \varepsilon}{\partial y}=\frac{\partial}{\partial x}\left[\left(\mu+\frac{\mu_{t}}{\sigma_{\varepsilon}}\right) \frac{\partial \varepsilon}{\partial x}\right]+\frac{\partial}{\partial y}\left[\left(\mu+\frac{\mu_{t}}{\sigma_{\varepsilon}}\right) \frac{\partial \varepsilon}{\partial y}\right]+ \\
\left(C_{\varepsilon 1} f_{1} P_{k}-\rho C_{\varepsilon 2} f_{2}\right)
\end{gathered}
$$

where: $\rho$ - Density $(\mathrm{kg} / \mathrm{m} 3), u$ Fluid velocity in $\mathrm{x}$ direction $(\mathrm{m} / \mathrm{s}) v$ Fluid velocity in y-direction $(\mathrm{m} / \mathrm{s})-\mu$ The molecularviscosity (Pa.s)- $\mu \mathrm{t}$ The turbulent (or eddy) viscosity (Pa.s)- $k$ Turbulent kinetic energy, $\left(\mathrm{m}^{2} / \mathrm{s}^{2}\right)-\sigma_{\varepsilon}$ Turbulent Prandtl number for $\varepsilon$-equation $\varepsilon$ Specific dissipation rate, $\mathrm{m}^{2} / \mathrm{s} 3 \quad-C_{\varepsilon 1}$ Constant$C_{\varepsilon 2}$ Constant- $f_{1}$ Constant $-f_{2}$ Constant

${ }^{p}{ }_{k}$ Represents the term of kinetic energy production

$$
P_{k}=\mu_{t}\left[2\left(\frac{\partial u}{\partial x}\right)^{2}+2\left(\frac{\partial v}{\partial y}\right)^{2}+\left(\frac{\partial v}{\partial x}+\frac{\partial u}{\partial y}\right)^{2}\right]
$$

Where: $u$ Fluid velocity in $\mathrm{x}$-direction( $\mathrm{m} / \mathrm{s}) v$ Fluid velocity in $\mathrm{y}$-direction $(\mathrm{m} / \mathrm{s}$ )- $\mu \mathrm{t}$ The turbulent (or eddy) viscosity (Pa.s)

\subsubsection{Turbulent viscosity: is calculated by:}

$$
\mu_{t}=f_{\mu} \rho \cdot C_{\mu} \frac{k^{2}}{\varepsilon}
$$


Where : $f_{\mu}$ Constant- $C_{\mu}$ Constant-k The turbulent kineticenergy $(\mathrm{m} 2 / \mathrm{s} 2)$. $\varepsilon$ The turbulent eddy dissipation (m2/s3).

The empirical constants of the standard K- $\varepsilon$ model are :

$$
\begin{gathered}
C_{\mu}=0.09 \quad, C_{\varepsilon 1}=C_{\varepsilon 2}=1.44, \sigma_{k}=1.0 \\
\sigma_{\varepsilon}=1.3, \sigma_{t}=0.9 \\
f_{1}=f_{2}=f_{\mu}=1
\end{gathered}
$$

2.2.7 The friction factor: is given by :

$\mathrm{f}=(0,790 \ln \mathrm{Re}-1,64)^{-2}$

$$
3000 \leq \operatorname{Re} \leq 5 \times 10^{6}
$$

\subsubsection{Reynolds Number :}

$$
R e=\rho U D h / \mu
$$

\subsubsection{Hydraulic diameter}

$$
D h=2 H W /(H+W)
$$

Where : H Channel height, (m) and W Channel Width, (m)

\subsubsection{Nusselt Number}

$$
N u=0,023 \operatorname{Re}^{4 / 5} \operatorname{Pr}^{0.4}
$$

Where Pr Prandtl Number

$$
R e \geq 10000
$$

\subsection{Boundary Condition}

The boundary conditions are identical for the three models and are as follows:

- air velocity inlet : $\cup_{0}=$ From 4 to $10 \mathrm{~m} / \mathrm{s}$.

- $\quad$ air temperature inlet $\mathrm{Te}=300^{\circ} \mathrm{K}$.

- The turbulent kinetic energy inlet $\mathrm{k}=0,005 \times$ $\mathrm{U}_{0}^{2}$

- $\quad$ dissipation energy inlet $\varepsilon=0.1 \cdot \mathrm{k}^{2}$

- Température absorbeur: $\mathrm{T}_{\mathrm{abs}}=380 \mathrm{~K}$.

- The temperature of the insulation and the baffles: $\mathrm{T}_{\text {iso }}=340 \mathrm{~K}$.

- Pression outlet : $\mathrm{P}_{\mathrm{s}}=$ Patm.

\section{Validation of results}

For the validation part we took the result of DIMARTINI [6] by comparing the velocity profiles for different vertical section

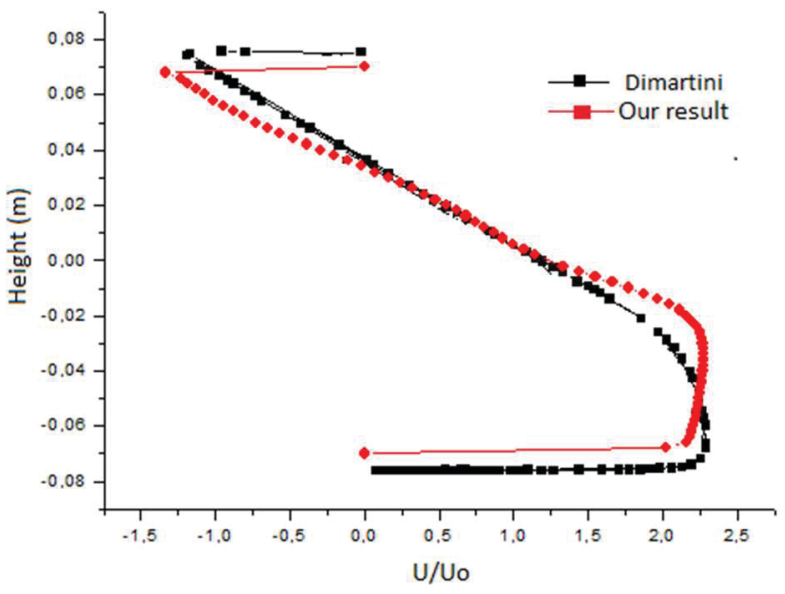

Fig. 2. Velocity profil for position $X=0.285 \mathrm{~m}$ $\mathrm{U}=7.8 \mathrm{~m} / \mathrm{s}$

Figures 2 shows that our results are very close to those of DIMARTINI [8], which means that our model is validated.

\section{Results and discussion}

In what follows we will present the results of our study, in the first part we will observe the velocity field, and in the second part we will observe the turbulence

\subsection{Velocity fields}

In what follows we will represent the velocity contours for different Reynolds value
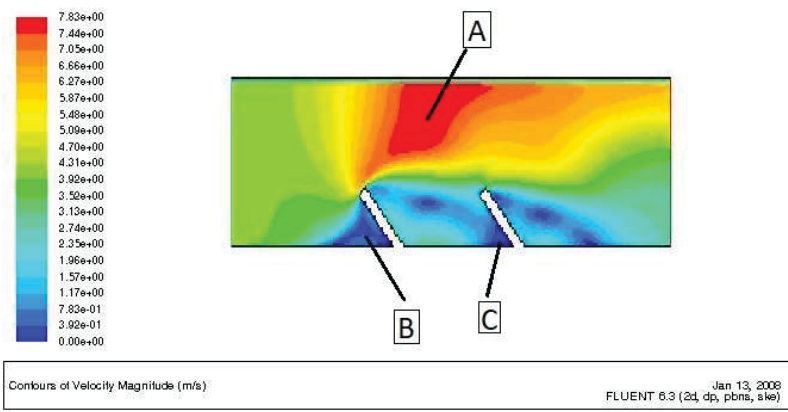

Fig. 3 Velocity Contour for $U$ inlet $=4 \mathrm{~m} / \mathrm{s}$ (Reynolds=59346)

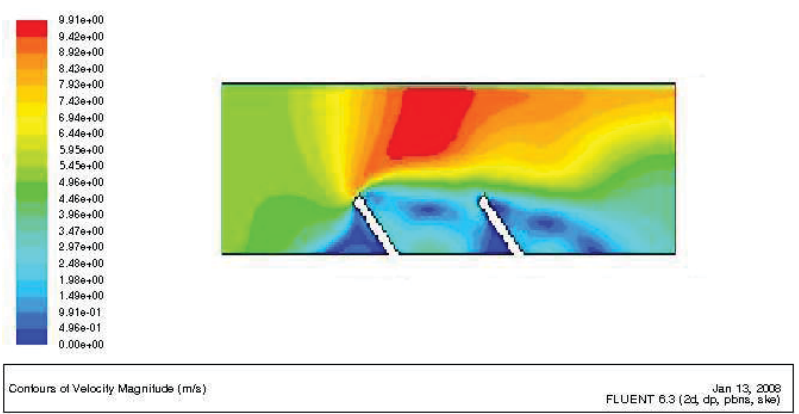

Fig. 4 Velocity Contour for $U$ inlet $=5 \mathrm{~m} / \mathrm{s}$ (Reynolds $=74$ 182) 


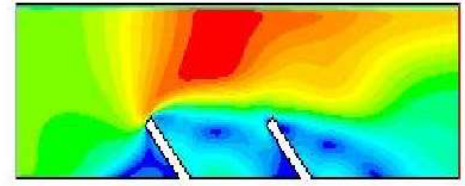

FLUENT 6.3 (20, dap, phns, 13,2006$)$

Fig. 5 Velocity Contour for $U$ inlet $=6 \mathrm{~m} / \mathrm{s}$ (Reynolds $=89072)$
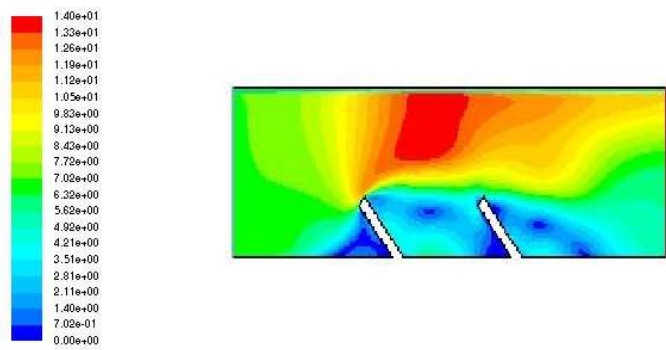

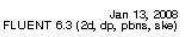

Fig. 6 Velocity Contour for U inlet $=7 \mathrm{~m} / \mathrm{s}$ $($ Reynolds $=103945)$
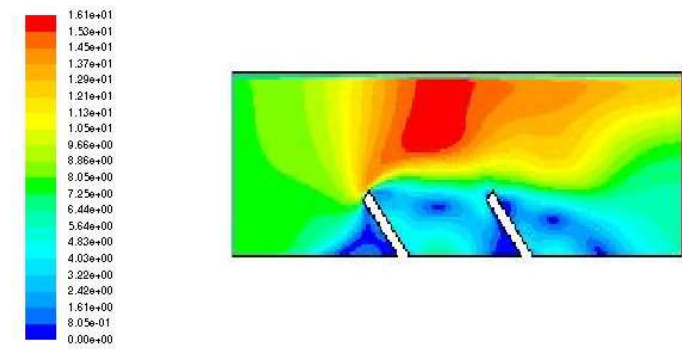

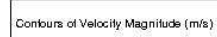

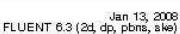

Fig. 8 Velocity Contour for U inlet $=8 \mathrm{~m} / \mathrm{s}$ $($ Reynolds $=118837)$
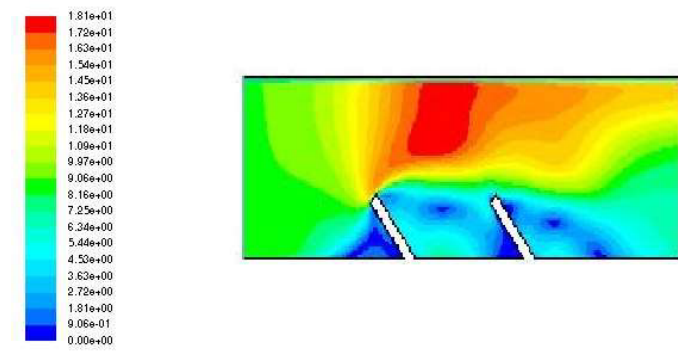

Conburs a Velecily Magituter (mos)

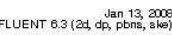

Fig. 9 Velocity Contour for U inlet $=9 \mathrm{~m} / \mathrm{s}$ $($ Reynolds $=133718)$
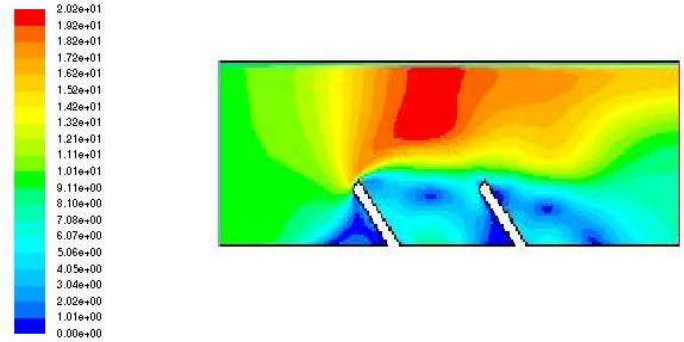

Conburs of Velocily Magniluds (mis) FLUENT $6.3(2 \mathrm{~d}, \mathrm{dp}, \mathrm{Jan}, 13,2008$

Fig. 10 Velocity Contour for $U$ inlet $=10 \mathrm{~m} / \mathrm{s}$

$($ Reynolds $=148$ 641)

From the analysis of the speed contours (figure 3 to $10)$, we are able to observe three zones, Zone A: recirculation zone, we observe that in this zone the value of the speed obtained is multiplied compared to that of the inlet by almost $100 \%$, i.e. double for all cases

Zone $\mathrm{B}$ and $\mathrm{C}$ : we observe that these are dead zones whose velocity values are almost zero or $0.392 \mathrm{~m} / \mathrm{s}$ for the first case (Figure 3 ) then this value grows with the increase in the Reynolds number with a percentega between $10 \%$ and $20 \%$.

\subsection{Turbulent kinetic energy}

In what follows we will represent the contour of the kinetic turbulence energy $\mathrm{K}$ for different Reynolds value

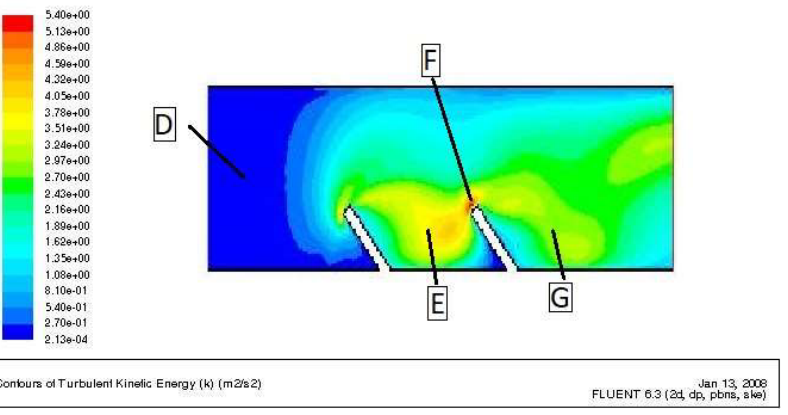

Fig. 11 Turbulent kinetic energy Contour for $\mathrm{U}$ inlet= $4 \mathrm{~m} / \mathrm{s}$ (Reynolds=59346)

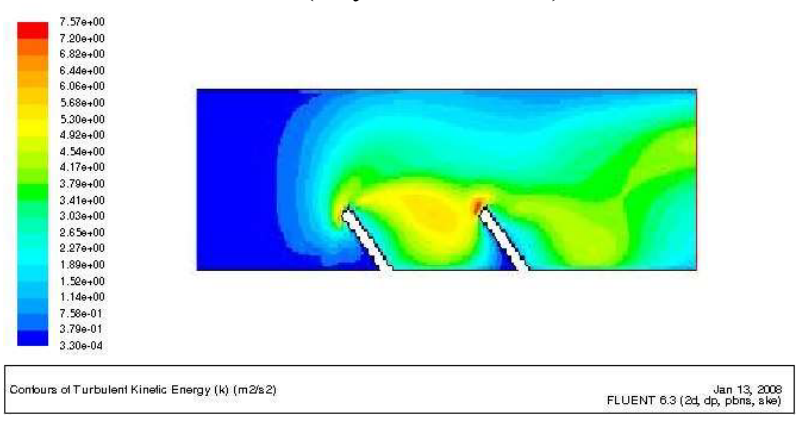

Fig. 12 Turbulent kinetic energy Contour for $U$ inlet= $5 \mathrm{~m} / \mathrm{s}$ (Reynolds $=74$ 182) 


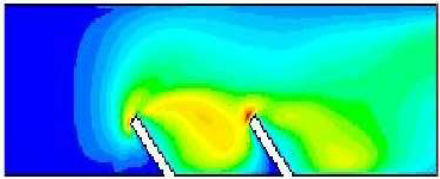

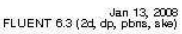

Fig. 13 Turbulent kinetic energy Contour for $U$ inlet= $6 \mathrm{~m} / \mathrm{s}$ (Reynolds $=89072)$

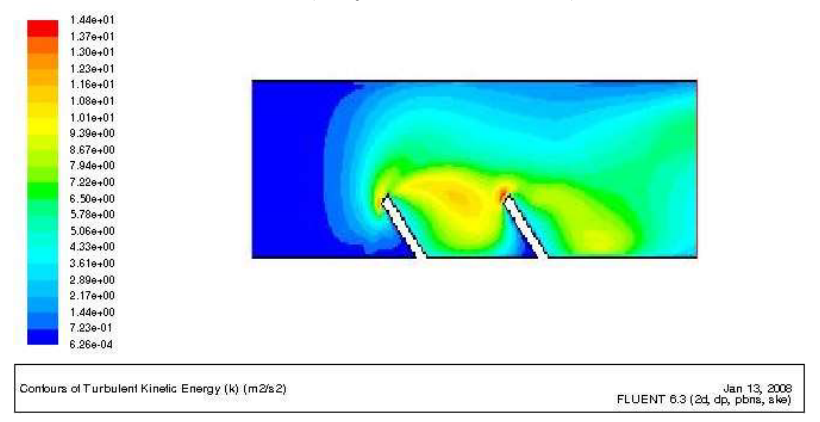

Fig. 14 Turbulent kinetic energy Contour for $U$ inlet $=7 \mathrm{~m} / \mathrm{s}($ Reynolds $=103945)$
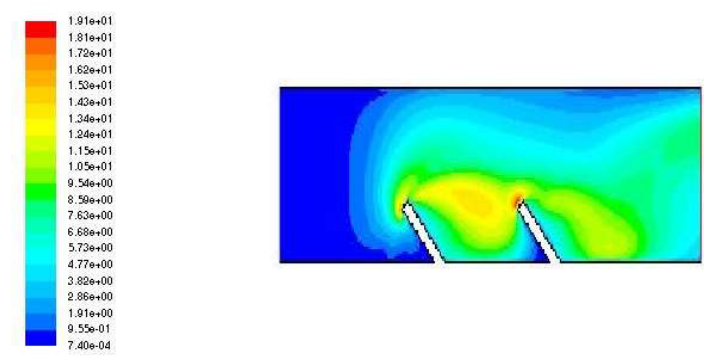

Fig. 15 Turbulent kinetic energy Contour for $\mathrm{U}$ inlet $=8 \mathrm{~m} / \mathrm{s}($ Reynolds $=118837)$
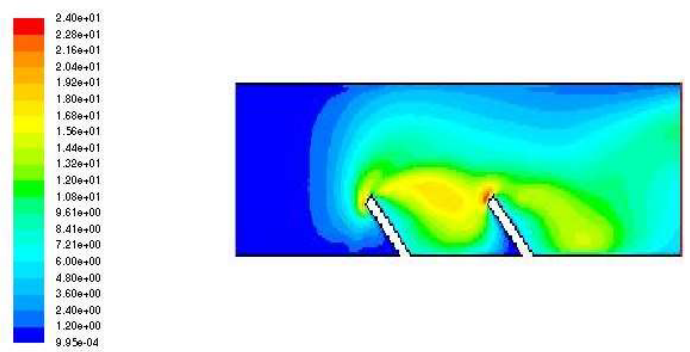
FLUENT 63 (a) Jan 13,2000

Fig. 16 Turbulent kinetic energy Contour for $\mathrm{U}$ inlet $=9 \mathrm{~m} / \mathrm{s}($ Reynolds $=133718)$
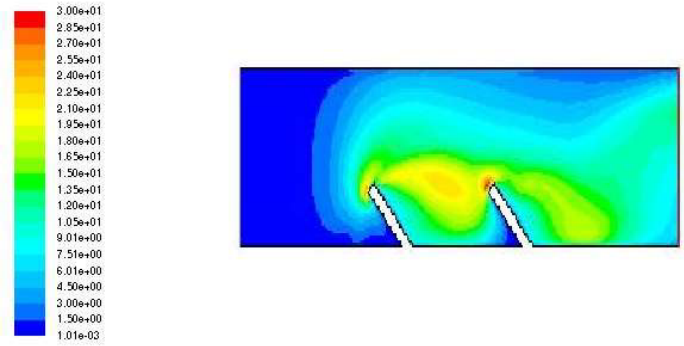

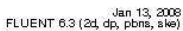

Fig. 17 Turbulent kinetic energy Contour for $U$ inlet $10 \mathrm{~m} / \mathrm{s}($ Reynolds $=148641)$

Figures 11 to 17 show us that the kinetic turbulence K increases with the increase of the Reynolds number we can observe four zones

Zone D, E, F, and G (see figure 11)

Zone D: where the turbulence is less important with a fixed value, this zone is located between the entrance and the first chicane.

Zone $\mathrm{E}$ between the two baffles

Zone $\mathrm{F}$ : at the end of the second chicane

Zone G: after the second chicance

For all cases the classification of the value of kinetic turbulence $\mathrm{K}$ in ascending order is, $\mathrm{D}, \mathrm{E}, \mathrm{G}$ and the most important $\mathrm{F}$

\subsection{The turbulent eddy dissipation}

In what follows we will represent the contours of the epsilon dissipation turbulence for different Reynolds value
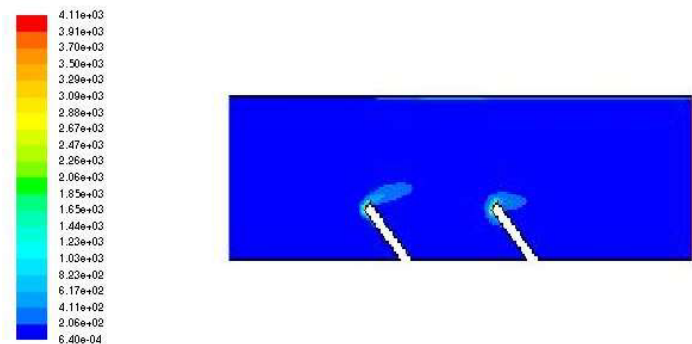

Fig. 18 Turbulent dissipation Contour for $U$ inlet $=4$ $\mathrm{m} / \mathrm{s}($ Reynolds $=59$ 346)
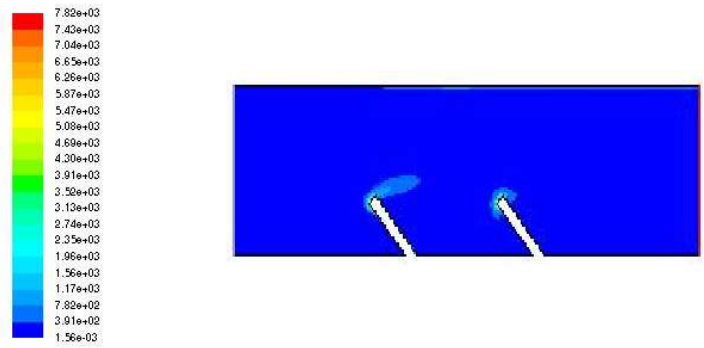

Fig. 19 Turbulent dissipation Contour for $\mathrm{U}$ inlet $=5$ $\mathrm{m} / \mathrm{s}$ (Reynolds $=74$ 182) 

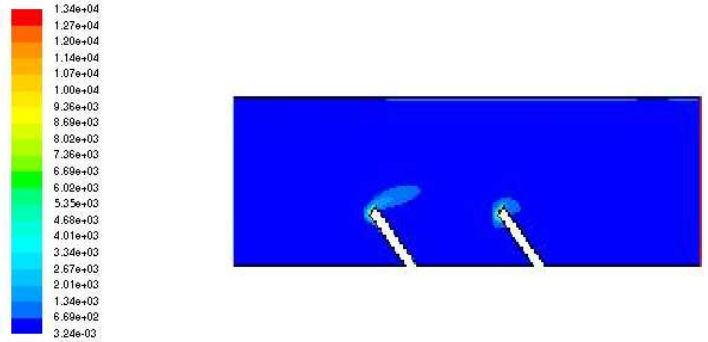

Conburs of Turbulent Diss ipation Fata (Epsilon) (mara3) FLUENT 6.3 (2d, dp, pan 13,2008

Fig. 20 Turbulent dissipation Contour for $U$ inlet $=6$ $\mathrm{m} / \mathrm{s}($ Reynolds $=89072)$
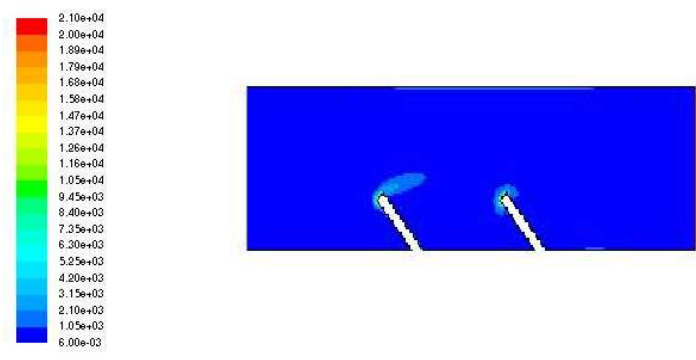

Conburs of Turbulant Diss ipation Fals (EFsilon) (m/ras) FLUENT 6.3 (24, dp, pan 13,2008

Fig. 21 Turbulent dissipation Contour for $U$ inlet $=7$ $\mathrm{m} / \mathrm{s}$ (Reynolds $=103945$ )
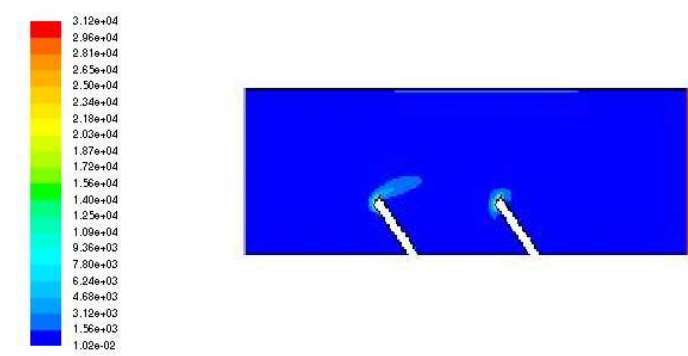

Fig. 22 Turbulent dissipation Contour for $\mathrm{U}$ inlet $=8$ $\mathrm{m} / \mathrm{s}($ Reynolds $=118837)$

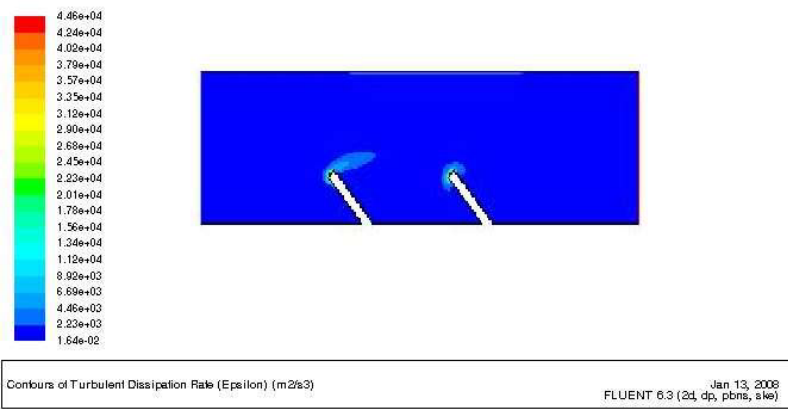

Fig. 23

Turbulent dissipation Contour for $U$ inlet $=9 \mathrm{~m} / \mathrm{s}$ (Reynolds $=133718)$
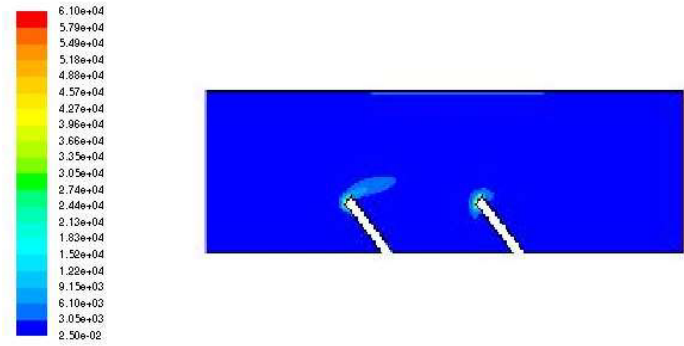

Fig. 24 Turbulent dissipation Contour for $U$ inlet $=10$ $\mathrm{m} / \mathrm{s}($ Reynolds $=148641)$

Following our analysis we can see that the more we increase the input speed, the more the dissipation turbulence increases (see figure 18 to 24 ), between the first and the last case in figures 18 and 24 the value of the dissipation energy is of 6.4 e- $4 \mathrm{~m} 2$ / s3 and 250 e-4 $\mathrm{m} 2 / \mathrm{s} 3$ respectively, i.e. 40 times

\subsection{NUSSELT number and friction Factor}

in what follows, and to better see the influence of the Reynolds number on the behavior of the solar collector we will plot the profiles of the nusselt number as well as that of the friction factor (figures 25 and 26)

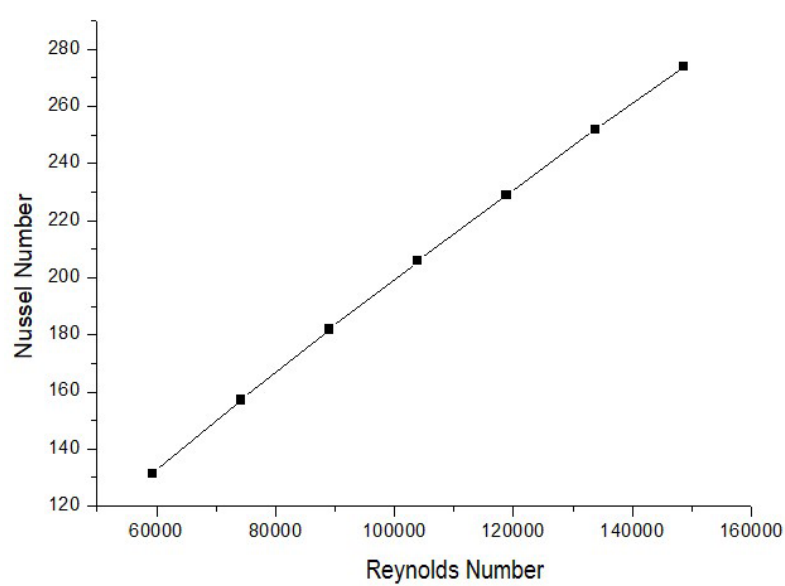

Fig. 25 Nusselt Number profile

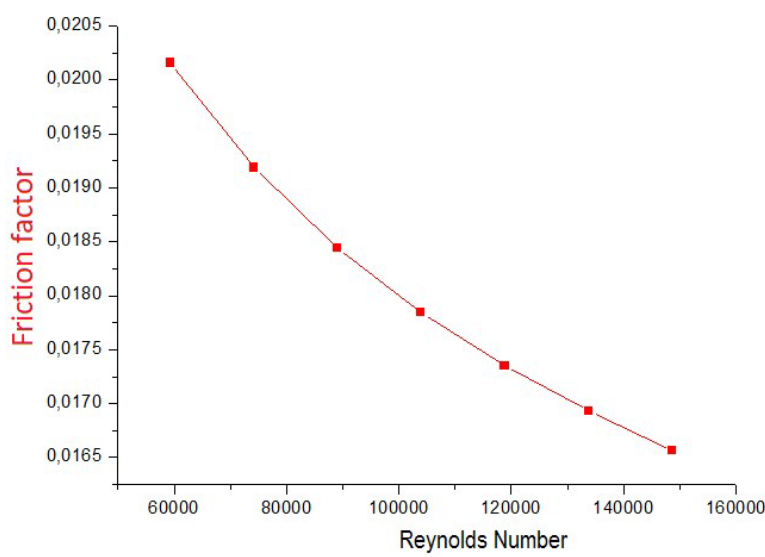

Fig. 26 Friction factor profile 
Figures 25 and 26 show us that the more the Reynold number increases, the more the value of the nusselt number increases, a maximum of 274 for a Reynolds number of 148641 and therefore a large heat transfer against the greater value of the factor friction and 0.0202 Which corresponds to the Reynold number of 131

\section{Conclusions}

In the present study, we have studied one of the many methods of improving the performance of a flat solar collector with baffles which is based on the variation of the Reynolds number

when the Reynold number is increased, the heat transfer also increases.

Nevertheless, this study must be accompanied by a technico-economic study in order to determine the real and useful energy needs in order to avoid any loss of energy

\section{References}

1. M. Jalil, H. Ayaal and A.Hardan, Numerical Investigation of Thermal Performance for Air Solar Collector with Multi Inlets, IOP Conf. Series: Materials Science and Engineering ICEMEAdoi:10.1088/1757-899X/765/1/012036 (2020) 2. G. Rodono and R. Volpes, Non-dimensional groups for air solar collectors, Energy and Buildings 35729 735 (2003)

3. G. Rodono and R. Volpes Heat transfer calculation in a free convection air solar collector, Energy and Buildings 27 21-27 (1998)

4. S. Oudjedi1*, A. Boubghal1, W. Braham Chaouch1, T. Cherguil et A. Belhamri Etude paramétrique d'un capteur solaire plan à air destiné au séchage, Revue des Energies Renouvelables SMSTS'08 Alger 255 - 266 (2008) 5. A. Aboltins, J. Palabinskis, A.Lauva, G Ruškis, Steel-Tinplate Absorber Investigations In Air Solar Collectors, Engineering for rural development jelgava, 28.-29.05. (2009).

6. S . Korobka, M. Babych, R . Krygul, A . Zdobytskyj, substantiation of parameters and operational modes of air solar collector, Eastern-European Journal of Enterprise Technologies ISSN 1729-3774 3/8 ( 93 ) (2018)

7. H Mzad, A Otmani, A Haouam, S. Łopata, and P Ocłoń, Tilt optimization of a double-glazed air solar collector prototype, MATEC Web of Conferences 240, 04006 (2018) ICCHMT (2018)

8. LC Demartini., H A Vielmo., S V Möller. Numeric and Experimental Analysis of the Turbulent Flow through a Channel WithBaffle Plates, Journal. of the Braz.Soc. ofMech. Sci. \& Eng, Vol. XXVI, No. 2 / 153 (2004), 